\title{
Peroxisome Proliferation in Liver of Rats Fed Oxidized Frying Oil
}

\author{
Pei-Min $\mathrm{CHAO}^{1}$, Mei-Fang $\mathrm{YANG}^{2}$, Yu-Na TSENG ${ }^{1}$, Ko-Ming $\mathrm{CHANG}^{3}$, Kuo-Shyan $\mathrm{Lu}^{3}$ \\ and Ching-jang $\mathrm{HUANG}^{4,5, *}$ \\ ${ }^{1}$ Department of Nutrition and ${ }^{2}$ Department of Anatomy, China Medical University, Taichung, 404, Taiwan \\ ${ }^{3}$ Department of Anatomy and Cell Biology, College of Medicine, National Taiwan University, Taipei, 100, Taiwan \\ ${ }^{4}$ Laboratory of Nutritional Biochemistry, Department of Biochemical Science and Technology and \\ ${ }^{5}$ Institute of Microbiology and Biochemistry, National Taiwan University, Taipei, 106, Taiwan
}

(Received April 15, 2005)

\begin{abstract}
Summary Oxidized frying oil (OFO) activates peroxisome proliferator-activated receptor $\alpha$ ( $\operatorname{PPAR} \alpha$ ) in vitro and in vivo. As most PPAR $\alpha$ activators are also peroxisome proliferators $(\mathrm{PP})$, this study was aimed at exploring whether OFO induces peroxisome proliferation in the liver of rats. Four groups of male weanling Sprague-Dawley rats were fed the following diets for $6 \mathrm{wk}$ : a basal diet containing $5 \mathrm{~g} / 100 \mathrm{~g}$ fresh soybean oil (LSB), high-fat diets containing $20 \mathrm{~g} / 100 \mathrm{~g}$ of fresh soybean oil (HSB as a control), OFO (HO) or fish oil (HF, as a positive control). Hepatomegaly and peroxisome proliferation in the liver of the $\mathrm{HO}$ group of rats were higher than those of the HF group. In addition, the acyl-CoA oxidase (ACO) activity, as well as cytochrome $\mathrm{P}_{450} 4 \mathrm{~A}$ (CYP4A) protein content in the livers of the HO group were 6 fold those of the HSB group, but were 2.5 fold in those of the HF group. These results indicated that dietary OFO induced typical responses to PPAR $\alpha$ signaling. Moreover, as a dietary source, the OFO prepared under our frying conditions appears to be a more potent peroxisome proliferator than fish oil.
\end{abstract}

Key Words oxidized frying oil, fish oil, acyl-CoA oxidase, cytochrome $\mathrm{P}_{450} 4 \mathrm{~A}$, peroxisome proliferation

Fat samples oxidized under more realistic cooking practices (frying) as part of a nutritional balanced diet gave rise to mild symptoms, such as: less body weight gain and feed intake, and enlargement of liver and kidney, in long term animal studies $(1,2)$. The modest biological effect could be attributed to a decreased digestion and absorption of the dimerized and polymerized TG $(3,4)$ as well as an effective detoxifying capability by the liver microsomal enzymes, including cytochrome $\mathrm{P}_{450}$ monoxygenase and phase II conjugation enzymes (5). The enlarged liver was thus speculated to be related to the increased microsomal protein since routine histopathological examination did not reveal significant alterations (Cheung and Huang, unpublished data).

Peroxisome proliferator (PP) refers to a group of

\footnotetext{
* To whom correspondence should be addressed.

E-mail: cjjhuang@ntu.edu.tw

Abbreviations: ACC, acety-CoA carboxylase; ACO, acyl-CoA oxidase; ACS, acyl-CoA synthetase; CFAM, cyclic fatty acid monomer; CLA, conjugated linoleic acid; CPT-I, carnitine palmitoyltransferase-I; CYP4A, cytochrome P450 4A; DHA, decoxahexaenoic acid; EPA, eicosapentaenoic acid; FAS, fatty acid synthase; LPL, lipoprotein lipase; MCAD, medium-chain acyl-CoA dehydrogenase; NEFA, non-esterified fatty acids; OFO, oxidized frying oil; PL, phospholipids; PNS, post-nuclear supernatant; PP, peroxisome proliferators; $\operatorname{PPAR} \alpha$, peroxisome proliferator-activated receptor $\alpha$; RXR, retinoid X receptor; SCD, stearoyl-CoA desaturase; SRE, sterol regulatory element; SREBP-1, sterol regulatory element binding protein-1; TC, total cholesterol; TG, triacylglycerol.
}

chemicals including hypolipidemic drugs, plasticizers, pesticides, and other compounds that cause an increase in the number and/or size of liver peroxisomes. Accompanied with peroxisome proliferation, a lower body weight, hepatomegaly, and an enhancing effect on the expression of fatty acid oxidation genes were consistently observed in PP-treated rodents (6).

A nuclear receptor cloned from the steroid hormone receptor family has been found to be activated by PP and named peroxisome proliferator-activated receptor (PPAR) (7). This ligand-dependent transcription factor is later shown to play a pivotal role in regulating liver lipid homeostasis (8-11). Upon activation by a ligand, PPAR heterodimerizes with retinoid X receptor (RXR) and promotes the transcription of its target genes through binding to a peroxisome proliferator responsive element (PPRE). The target genes of PPAR $\alpha$ are mainly a homogeneous group of genes that participate in aspects of lipid catabolism and lipoprotein assembly and transport (12).

Using gene knockout mice, the pleiotropic effects of PP were shown to be $\operatorname{PPAR} \alpha$-dependent (13). The intensity of peroxisome proliferation response induced by PP among various tissues and species was closely related to their PPAR $\alpha$ activating potency $(7,14)$.

We $(15,16)$ and others $(17)$ reported that the expression of PPAR $\alpha$ target genes in the liver of rats was upregulated by feeding an oxidized frying oil-containing diet. Results of transactivation assay in which hydrolyzed OFO showed a higher potency in activating 
PPAR $\alpha$ than hydrolyzed fresh soybean oil indicated that the up-regulation was through the activation of $\operatorname{PPAR} \alpha$ (15). It is conceivable that certain product(s) formed from TG during the frying process in the OFO may be absorbed and act as PPAR $\alpha$ activator(s) in the body. A number of PPAR $\alpha$ activators have been identified from diet/food origin, such as fish oil, conjugated linoleic acid (CLA) in ruminant animal products, chlorophyllderived phytol/phytanic acid and soy isoflavone. In rodents, fish oil (18) and phytol/phytanic acid $(19,20)$ were shown to give rise to peroxisome proliferation, but not CLA, at a dose of up to $1.5 \%$ (wt/wt) for $6 \mathrm{wk}(21)$. CLA has been detected in certain heated vegetable oil samples collected from restaurants (22).

This study, therefore, was conducted to examine if OFO feeding, like administration of most PP or PPAR $\alpha$ activators, induced liver peroxisome proliferation along with the up-regulation of PPAR $\alpha$ target genes. Peroxisome proliferation cannot be identified by routine histopathological procedures; this study thus examined the liver sections of rats fed a $20 \%$ (wt/wt) OFO diet, using a peroxisome-specific histochemical staining, i.e. DAB for catalase activity. Rats fed a $20 \%$ fish oil diet were included as a positive control. Other biochemical parameters generally altered by the administration of $\operatorname{PPAR} \alpha$ activators, were also examined.

\section{MATERIALS AND METHODS}

Animals and diets. Male weanling Sprague-Dawley rats weighing $50-70 \mathrm{~g}$ were purchased from the laboratory animal center of the National Science Council (Taipei, Taiwan). Weight-matched rats were divided into four groups ( $n=8$ for each group) fed with a lowfat diet containing $5 \mathrm{~g} / 100 \mathrm{~g}$ fresh soybean oil (LSB) or

Table 1. The fatty acid composition of fresh soybean oil, oxidized frying oil, and fish oil used in the test diets. $^{1,2}$

\begin{tabular}{lccc}
\hline & $\begin{array}{c}\text { Fresh } \\
\text { soybean oil }\end{array}$ & $\begin{array}{c}\text { Oxidized } \\
\text { frying oil }\end{array}$ & Fish oil \\
\hline 14:0 & - & (g/100 g oil) & \\
$16: 0$ & 11 & - & 5 \\
$16: 1$ & - & - & 8 \\
$18: 0$ & 5 & 4 & 8 \\
$18: 1$ & 22 & 21 & 1 \\
$18: 2$ & 53 & 33 & 10 \\
$18: 3$ & 9 & 3 & 1 \\
$20: 4 n-6$ & - & - & 1 \\
$20: 5 n-3$ & - & - & 29 \\
$22: 1$ & - & - & 1 \\
$22: 6 n-3$ & - & - & 14 \\
Unidentified & 0 & 28 & 20
\end{tabular}

${ }^{1}$ Oxidized frying oil was prepared by frying dough sheets in soybean oil (President Co., Tainan, Taiwan) at 205士 $5^{\circ} \mathrm{C}$ for $24 \mathrm{~h}$.

${ }^{2}$ Source of fish oil: TAMA Biochemical Co., Kanagawa, Japan. high-fat diets containing $20 \mathrm{~g} / 100 \mathrm{~g}$ fresh soybean oil (HSB), OFO (HO) or fish oil (HF) respectively. All rats were housed individually in stainless steel wire cages in a room maintained at $23 \pm 2^{\circ} \mathrm{C}$, with a controlled $12-\mathrm{h}$ light : dark cycle and free access to tap water. Since the OFO-containing diet significantly reduced the feed intake, all rats in LSB, HSB and HF groups were pair-fed isocalorically with $\mathrm{HO}$ group, which was the only group fed ad libitum. The body weight gain and food intake were recorded weekly. Animal care and handling conformed to accepted guidelines (23).

The OFO was prepared by frying wheat dough sheets in soybean oil (President, Tainan, Taiwan) at $205 \pm 5^{\circ} \mathrm{C}$ for $24 \mathrm{~h}$, and the extent of oxidation was as described previously (15). The fatty acid composition of fresh soybean oil, OFO and fish oil used in the test diets is shown in Table 1. The composition of the four test diets is shown in Table 2 in which the amounts of casein, vitamin and mineral mixtures in the three high-fat diets were adjusted to ensure that the nutrients/energy ratio was equivalent among the four diets.

Tissue sampling and preparation. After $6 \mathrm{wk}$ of feeding, rats were killed by carbon dioxide asphyxiation after overnight fasting. Blood was collected from the abdominal vena cava with EDTA-containing tubes. The liver was excised and weighed, and a small portion was frozen at $-20^{\circ} \mathrm{C}$ for the analysis of lipid content. A sec-

Table 2. Composition of test diets used in the feeding experiment. $^{1,2}$

\begin{tabular}{lrrrr}
\hline & LSB & HSB & HO & HF \\
\hline & \multicolumn{4}{c}{ (g/kg diet) } \\
Casein & 200 & 235 & 235 & 235 \\
Corn starch & 650 & 448 & 448 & 448 \\
Fresh soybean oil & 50 & 200 & - & 5 \\
$\begin{array}{l}\text { Oxidized frying oil } \\
\text { Fish oil }\end{array}$ & - & - & 200 & - \\
Cellulose & 50 & 59 & 59 & 59 \\
Mineral mixtures & 35 & 41 & 41 & 41 \\
Vitamin mixture & 10 & 12 & 12 & 12 \\
$\begin{array}{l}\text { DL-Methionine } \\
\text { Choline }\end{array}$ & 3 & 3 & 3 & 3 \\
$\begin{array}{l}\text { Calorie density } \\
\text { (kcal/g) }\end{array}$ & 3.85 & 4.53 & 4.53 & 4.53 \\
$\begin{array}{l}\text { Protein/calorie } \\
\text { (g/1,000 kcal) }\end{array}$ & 52 & 52 & 52 & 52 \\
$\begin{array}{l}\text { Vitamins/calorie } \\
\text { (g/1,000 kcal) }\end{array}$ & 2.6 & 2.6 & 2.6 & 2.6 \\
$\begin{array}{l}\text { Minerals/calorie } \\
\text { (g/1,000 kcal) }\end{array}$ & 9 & 9 & 9 & 9 \\
\hline
\end{tabular}

${ }^{1}$ The four test diets were a low-fat diet containing fresh soybean oil (LSB) or high-fat diets containing fresh soybean oil (HSB), oxidized frying oil (HO) or fish oil (HF). ${ }^{2}$ Sources of ingredients: casein, ICN (Aurora, OH); cornstarch, Samyang (Seoul, Korea); cellulose, J. Rettenmaier \& Söhne (Holzmühle, Germany); methionine and choline chloride, Sigma Chemical (St. Louis, MO); AIN-76 mineral mixture and AIN-76 vitamin mixture, ICN (Aurora, $\mathrm{OH})$. 
ond portion $\left(0.5 \mathrm{~cm}^{3}\right)$ was cut and immersed in a fixative containing $1.5 \%$ glutaraldehyde and $4 \%$ paraformaldehyde in $0.1 \mathrm{M}$ cacodylate buffer $(\mathrm{pH} 7.2)$ at $4^{\circ} \mathrm{C}$ for $24 \mathrm{~h}$ for histological analysis. Remaining portions of the liver were freshly homogenized in $0.05 \mathrm{~mol} / \mathrm{L}$ phosphate buffer ( $\mathrm{pH}$ 7.4) for the preparation of postnuclear supernatant (PNS) and microsome as previously described (15). Plasma samples were obtained by centrifugation of blood and stored at $-20^{\circ} \mathrm{C}$ for the analysis of lipids.

Histological analysis. For localization of peroxisomes in hepatocytes, cytochemical staining of catalase with 3,3'-diaminobenzidine (DAB) was used (24). After being fixed for $48 \mathrm{~h}$ at $4^{\circ} \mathrm{C}$, the liver specimens were cut into $30 \mu \mathrm{m}$ vibrotome sections. The sections were then rinsed in $0.1 \mathrm{M}$ glycine- $\mathrm{NaOH}$ buffer ( $\mathrm{pH} 10.5$ ) containing $7.5 \%$ sucrose, and subsequently incubated with $5 \mathrm{mM} \mathrm{DAB}$ and $0.15 \% \mathrm{H}_{2} \mathrm{O}_{2}$ in $0.1 \mathrm{M}$ glycine- $\mathrm{NaOH}$ buffer for $30 \mathrm{~min}$ at room temperature. At completion of incubation, the vibrotome sections were trimmed into $1 \mathrm{~mm}^{2}$, rinsed thoroughly with glycine- $\mathrm{NaOH}$ buffer, postfixed in 1\% osmium tetroxide for $20 \mathrm{~min}$, dehydrated through a graded series of ethanol, and embedded in Epon 812. The Epon-embedded specimens were cut into $1 \mu \mathrm{m}$-thick sections, stained with $0.2 \%$ toluidine blue, and examined under a light microscope. For quantification of the extent of peroxisome proliferation, a total of 75 cells, randomly chosen from five liver sections for individual rats in each group, were counted for the peroxisome number in each cell. The data were expressed as peroxisome number/per cell and statistically analyzed.

Biochemical analyses. For the analysis of liver lipids, frozen liver samples were thawed and extracted by the method of Folch et al. (25). Total lipids, triacylglycerol (TG), total cholesterol (TC), and non-esterified fatty acids (NEFA) in plasma and liver lipid extract were measured enzymatically with a commercial kit (Randox lab, Crumlin, Northland, UK). The peroxisomal acyl-CoA oxidase (ACO) activities in PNS of liver were determined by the method of Small et al. (26). Briefly, $1 \mathrm{~mL}$ reaction mixture containing $0.05 \mathrm{~mm}$ leuco-dichlorofluorescein (DCF), $0.08 \mathrm{~mm}$ horseradish peroxidase, $40 \mathrm{~mm}$ aminotriazole, $0.02 \%$ Triton $\mathrm{X}-100,11 \mathrm{~mm}$ potassium phos- phate buffer, $\mathrm{pH} 7.4$, and an appropriate volume of PNS was pre-incubated in the dark for $10 \mathrm{~min}$. Then the enzymatic reaction was started with the addition of $30 \mu \mathrm{M}$ palmitoyl-CoA and the absorbance at $502 \mathrm{~nm}$ was traced by UV/VIS spectrophotometer (Hitachi U2000, Japan). The cytochrome $\mathrm{P}_{450} 4 \mathrm{~A}$ (CYP4A) protein in liver microsomal suspension was detected by Western blot analysis as previously described (15). Briefly, $5 \mu \mathrm{g}$ liver microsomal protein was subjected to $10 \%$ SDS-PAGE, then transferred to a polyvinylidene fluoride-plus transfer membrane (NEN Life Science, Boston, MA). The blot was immunodetected with a enhanced chemiluminescence Western blotting kit (Amersham International, Amersham, UK) in which sheep anti-rat CYP4A was used as the primary antibody and a biotinylated donkey anti-sheep immunoglobulin $\mathrm{G}$ was used as the secondary antibody.

Statistical analysis. Data were expressed as mean \pm SD of eight rats in each group. Student's $t$ test was used for the comparison between low-fat and high-fat control groups (LSB and HSB). The significance of differences among the three high-fat diet groups (HSB, HO and HF) was analyzed statistically by one-way ANOVA and Duncan's multiple range test. Data were transformed to $\log$ values for the statistical analysis if the variances were not homogeneous. The General Linear Model of the SAS package (SAS Institute, Cary, NC) was employed for both statistical analyses and differences were considered significant at $p<0.05$.

\section{RESULTS}

\section{Body weight and relative tissue weight}

Since all rats were fed isocalorically, the body weight gain was not different between low-fat and high-fat diet-fed rats as expected, except for the HO group (Table 3). The HO-fed rats had significantly lower body weight gain than HSB and HF groups of rats $(p<0.005$, Table $3)$. The relative weight of the liver and kidney of the HO and HF groups were significantly higher than those of the HSB group $(p<0.05)$, indicating enlargement of the liver and kidney in rats fed the high OFO and high fish oil diet. Compared to the LSB group, rats in the HSB groups had significantly higher weight of epididymal and retroperitoneal fat pads $(p<0.05$, Table 3$)$. In con-

Table 3. Body weight gain and relative tissue weight of rats fed with a low-fat diet containing $5 \mathrm{~g} / 100 \mathrm{~g}$ fresh soybean oil (LSB) or high-fat diets containing $20 \mathrm{~g} / 100 \mathrm{~g}$ fresh soybean oil (HSB), oxidized frying oil (HO) or fish oil (HF). ${ }^{1,2}$

\begin{tabular}{lccccc}
\hline & $\begin{array}{c}\text { Body weight gain } \\
(\mathrm{g})\end{array}$ & Liver & $\begin{array}{c}\text { Kidney } \\
(\mathrm{g} / 100 \mathrm{~g} \text { body weight })\end{array}$ & $\begin{array}{c}\text { Epididymal fat } \\
\text { Retroperitoneal fat }\end{array}$ \\
\hline LSB & $203 \pm 7$ & $3.21 \pm 0.32$ & $0.88 \pm 0.06$ & $1.05 \pm 0.27^{*}$ & $1.24 \pm 0.20^{*}$ \\
HSB & $204 \pm 15^{\mathrm{a}}$ & $3.37 \pm 0.27^{\mathrm{c}}$ & $0.83 \pm 0.06^{\mathrm{b}}$ & $1.35 \pm 0.16^{\mathrm{a}}$ & $1.53 \pm 0.37^{\mathrm{a}}$ \\
HO & $183 \pm 15^{\mathrm{b}}$ & $5.69 \pm 0.37^{\mathrm{a}}$ & $0.99 \pm 0.06^{\mathrm{a}}$ & $1.14 \pm 0.22^{\mathrm{b}}$ & $0.62 \pm 0.31^{\mathrm{c}}$ \\
HF & $212 \pm 22^{\mathrm{a}}$ & $4.18 \pm 0.36^{\mathrm{b}}$ & $1.01 \pm 0.07^{\mathrm{a}}$ & $1.02 \pm 0.26^{\mathrm{b}}$ & $1.14 \pm 0.33^{\mathrm{b}}$ \\
\hline
\end{tabular}

${ }^{1}$ Values are mean \pm SD, $n=8 .{ }^{*}$ denotes a significant difference $(p<0.05)$ between the LSB and HSB groups analyzed by Student's $t$-test. The significance of difference among the HSB, HO and HF groups was analyzed by one-way ANOVA and Duncan's multiple range test. Values not sharing a superscript letter are significantly different $(p<0.05)$.

${ }^{2}$ Body weight gain=final body weight (at $6 \mathrm{wk}$ )-initial body weight (at $\left.0 \mathrm{wk}\right)$. 

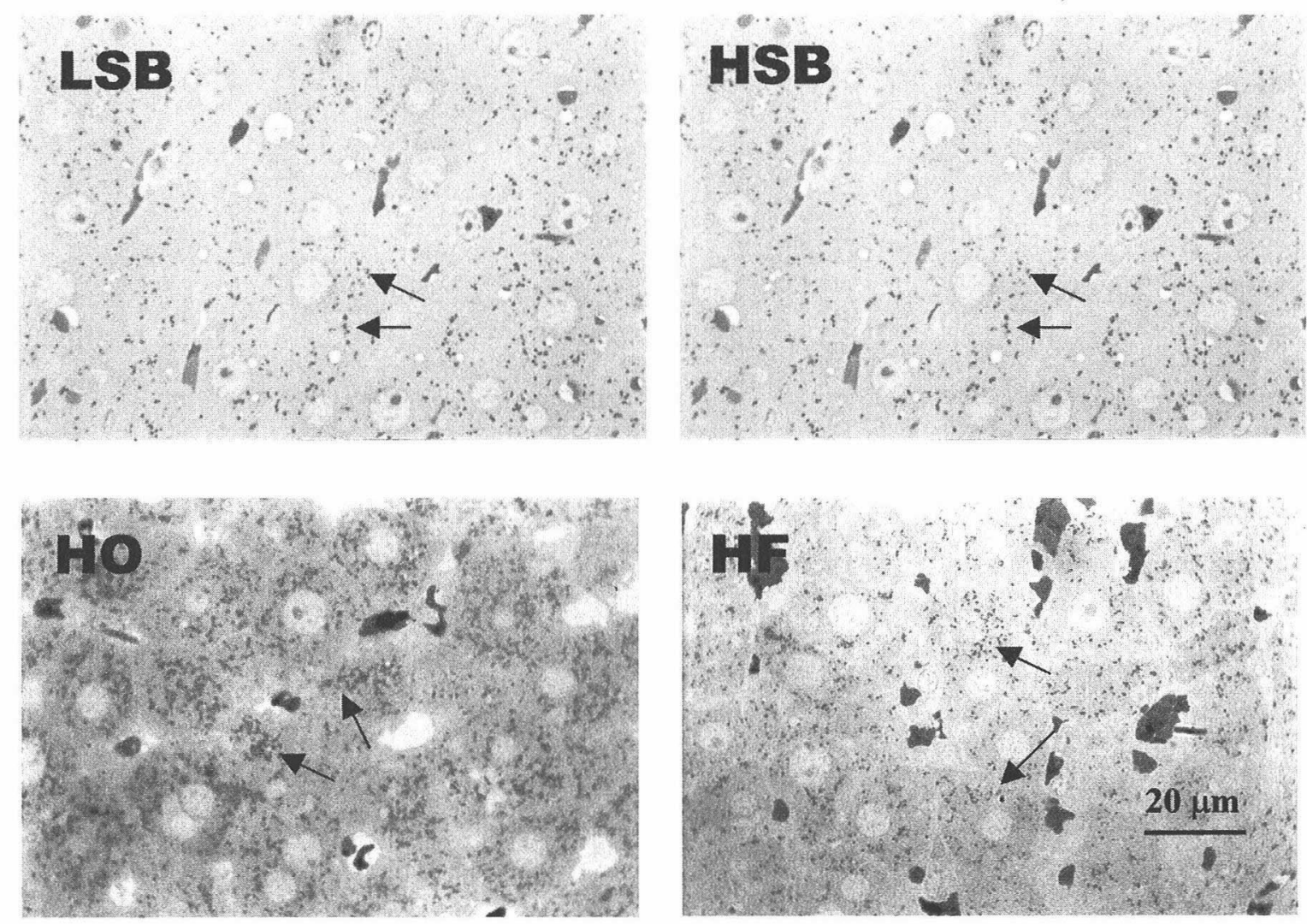

\begin{tabular}{|c|c|c|c|c|}
\hline Group & LSB & HSB & HO & HF \\
\hline $\begin{array}{c}\text { Peroxisome number } \\
\text { /cell }\end{array}$ & $13 \pm 5$ & $13 \pm 5^{\circ}$ & $70 \pm 20^{\mathrm{a}}$ & $34 \pm 8^{\mathrm{b}}$ \\
\hline
\end{tabular}

Fig. 1. Photomicrographs of the liver sections were stained for catalase with 3,3'-diaminobenzidine and then counterstained with toluidine blue and the number of peroxisomes counted. Peroxisomes are darkly stained particles (arrows) in the cytoplasm of hepatocytes and the counted numbers per cell are shown under the graph (mean \pm SD) ( 3 rats in each group and 75 cells per rat were counted). The significance of difference among the HSB, HO and HF groups was analyzed by one-way ANOVA and Duncan's multiple range test. Values not sharing a common letter a, b, or c are significantly different $(p<0.05)$. There was no difference $(p>0.05)$ between LSB and HSB groups analyzed by Student's $t$ test. Photomicrographs shown are representatives of the four groups. Scale bar $=20 \mu \mathrm{m}$.

trast, rats fed the $\mathrm{HO}$ and HF diets showed significantly reduced epididymal and retroperitoneal fat pads weight compared to the HSB group ( $p<0.05$, Table 3$)$. The retroperitoneal fat pad weight of the $\mathrm{HO}$ and $\mathrm{HF}$ groups were $40 \%$ and $70 \%$ that of the HSB group, respectively, indicating the retarded accumulation of abdominal fat is more prominent in the $\mathrm{OFO}$ fed rats than in the fish oil fed rats $(p<0.05)$.

Hepatic abundance of peroxisome

Since hepatic proliferation of peroxisome generally is accompanied by PPAR $\alpha$ activation in rodents, liver sections of the tested rats were stained histochemically with $\mathrm{DAB}$ for catalase to locate peroxisomes in cytoplasm. There was a comparable number of peroxisomes stained as dark particles per cell in the liver section of low and high fresh soybean oil-fed rats ( $13 \pm 5 /$ cell for LSB and 13 $\pm 5 /$ cell for HSB group; Fig. 1). However, in the liver section of the HO group rats, the number of peroxisomes was significantly higher than that of the
HSB group ( $70 \pm 20 /$ cell vs. $13 \pm 5 /$ cell, $p<0.00001$ ), indicating a marked peroxisome proliferation (about 5.5 fold those of fresh soybean oil-fed rats) in the liver of rats fed the high OFO diet. The liver of rats fed the high fish oil diet also showed a proliferation of peroxisome ( $34 \pm 8 /$ cell, 2.6 fold those of fresh soybean oil-fed rats), but to a significantly lesser extent than that in the HO group (HF vs. HO, $p<0.00001$ ).

Hepatic peroxisomal ACO activity and CYP4A protein content

Among the four groups, rats fed the HO diet had the highest hepatic ACO activity (Fig. 2) and CYP4A protein content (Fig. 3). The ACO activity and microsomal CYP4A protein content of the HO group were about 6 fold those of the HSB group $(p<0.05)$. The ACO activity and CYP4A protein content in the liver of the HF group were 2.5 fold those of the HSB group $(p<0.05)$. These results imply an activation of the liver PPAR $\alpha$-signaling pathway in both groups of rats fed the high OFO and 
fish oil diets, but the extent was significantly less in rats fed the fish oil diet than in rats fed the OFO diet. The induction folds of these two PPAR $\alpha$ target genes by dietary OFO and fish oil agree with the induction folds

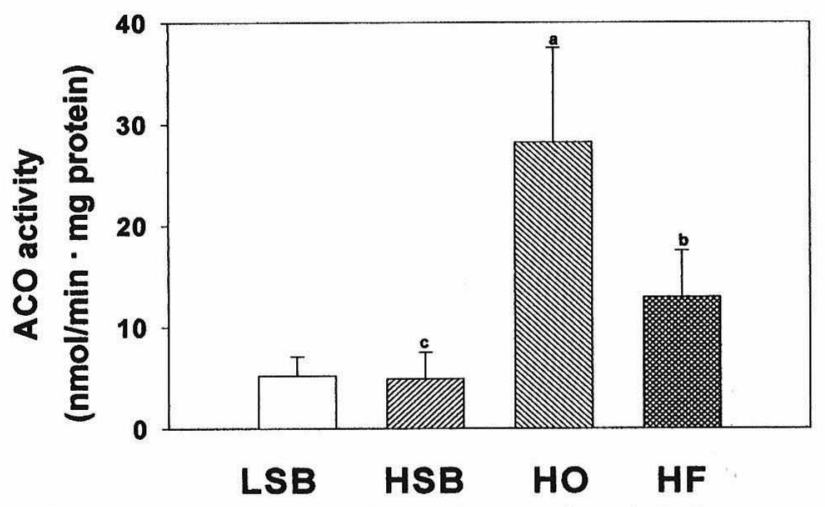

Fig. 2. The peroxisomal acyl-CoA oxidase (ACO) activity in the liver of rats fed with a low-fat diet containing $5 \mathrm{~g} / 100 \mathrm{~g}$ fresh soybean oil (LSB) or high-fat diets containing $20 \mathrm{~g} / 100 \mathrm{~g}$ fresh soybean oil (HSB), oxidized frying oil (HO) or fish oil (HF). The significance of difference among the HSB, HO and HF groups was analyzed by one-way ANOVA and Duncan's multiple range test. Values not sharing a common letter $\mathrm{a}, \mathrm{b}$, or $\mathrm{c}$ are significantly different $(p<0.05)$. There was no difference ( $p>0.05$ ) between the LSB and HSB groups analyzed by Student's $t$ test.
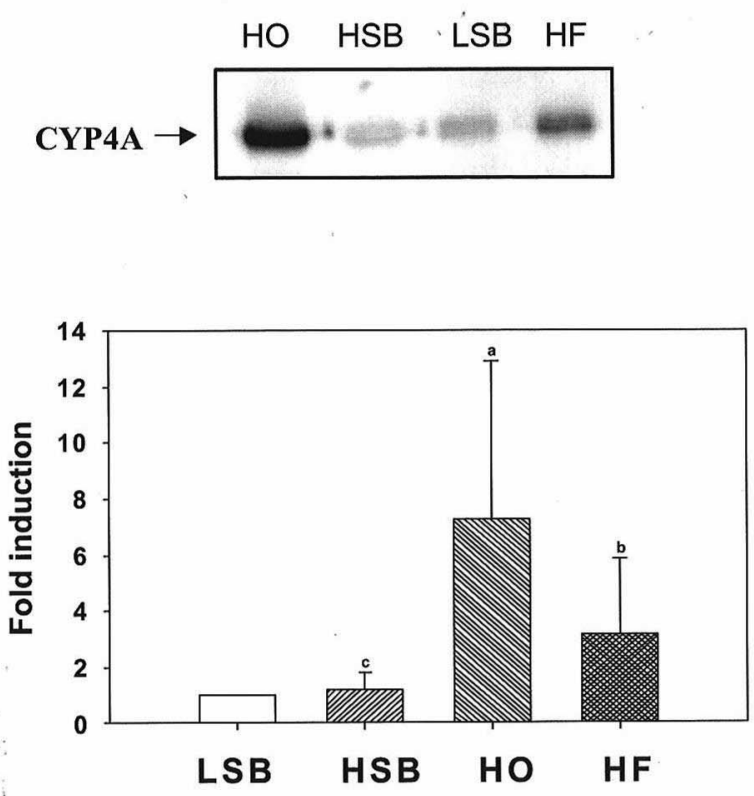

Fig. 3. The Western blot of microsomal cytochrome $\mathrm{P}_{450} 4 \mathrm{~A}$ (CYP4A) in the liver of rats fed with a low-fat diet containing $5 \mathrm{~g} / 100 \mathrm{~g}$ fresh soybean oil (LSB) or high-fat diets containing $20 \mathrm{~g} / 100 \mathrm{~g}$ fresh soybean oil (HSB), oxidized frying oil (HO) or fish oil (HF). The significance of difference among the HSB, HO and HF groups was analyzed by one-way ANOVA and Duncan's multiple range test. Values not sharing a common letter $\mathrm{a}, \mathrm{b}$, or $\mathrm{c}$ are significantly different $(p<0.05)$. There was no difference $(p>0.05)$ between the LSB and HSB groups analyzed by Student's $t$ test.
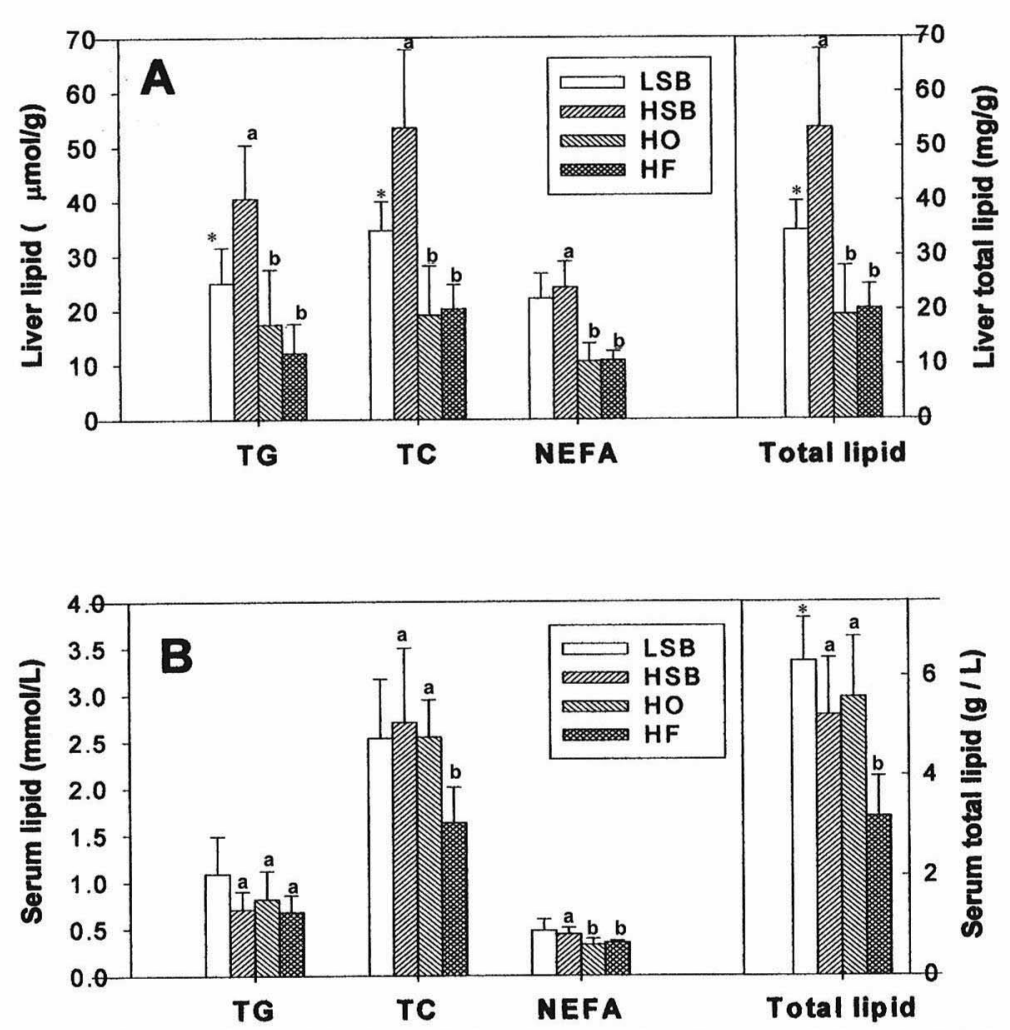

Fig. 4. The liver lipids (A) and serum lipids (B) of rats fed with a low-fat diet containing $5 \mathrm{~g} / 100 \mathrm{~g}$ fresh soybean oil (LSB) or high-fat diets containing $20 \mathrm{~g} / 100 \mathrm{~g}$ fresh soybean oil (HSB), oxidized frying oil (HO) or fish oil (HF). * denotes a significant difference $(p<0.05)$ between the LSB and HSB groups which was analyzed by Student's $t$-test. The significance of difference among the HSB, HO and HF groups was analyzed by one-way ANOVA and Duncan's multiple range test. Values not sharing a common letter a or b are significantly different $(p<0.05)$. TG, triacylglycerol; TC, total cholesterol; NEFA, nonesterified fatty acids. 
of peroxisome proliferation. There was no significant difference in the peroxisomal ACO activity and microsomal CYP4A protein content between the LSB and HSB diet groups $(p>0.05)$.

Effects on liver and serum lipids

It is generally accepted that the activation of the $\operatorname{PPAR} \alpha$-signaling pathway may lead to an increased hepatic fatty acids $\beta$ - and $\omega$-oxidation by the up-regulation of the expression of genes involved in fatty acid catabolism; this in turn results in a lower liver/blood lipid. Therefore, the liver and serum lipids were also determined. As shown in Fig. 4A, the liver TG, TC, and total lipid were all significantly increased by the high fresh soybean oil diet $(p<0.05$, HSB vs. LSB). As expected, a significant reduction of all classes of liver lipids (TG, TC, NEFA, and total lipid) was observed in HO- and HF-fed rats $(p<0.0001, \mathrm{HO}$ and HF vs. HSB). However, although the HO diet regimen induced a higher peroxisome proliferation response than the HF diet, the liver lipids level was not different between the HO and HF diet groups $(p>0.05)$. In contrast to the lipid profile in the liver, serum lipids were not increased by the high fresh soybean oil diet ( $p>0.05$, HSB vs. LSB, Fig. 4B). Rats fed the HO and HF diet had significantly lower serum NEFA $(p<0.05)$ than rats fed the HSB diet. In addition, the HF group showed a significantly lower serum TC and total lipid level than the HSB group $(p<0.05)$.

\section{DISCUSSION}

Peroxisomes are spherical oval bodies of $0.3-1.0 \mu \mathrm{m}$ in diameter with a single limiting membrane and a finely granular matrix. These organelles contain both hydrogen peroxide producing (flavin-containing oxidases) and degrading (catalase) enzymes. Some of the most important metabolic functions of peroxisomes include the synthesis of plasmalogens, bile acids, cholesterol and dolichol, the oxidation of fatty acids (very long chain fatty acids $\geqq \mathrm{C} 22$, branched chain fatty acids [eg. Phytanic acid], dicarboxylic acids, unsaturated fatty acids, prostaglandins, pipecolic acid and glutaric acid), and metabolism of purines, polyamines, amino acids, glyoxylates, and reactive oxygen species. Human peroxisome diseases result from the dysfunction of one or more peroxisomal metabolic functions, the majority of which manifest as neurological abnormalities (27). On the other hand, peroxisome proliferation in the liver of rodents induced by PP is often associated with nongenotoxic liver cancer, but this does not occur in humans (28).

Results of this study showed that the 20\% OFO diet not only up-regulated PPAR $\alpha$ target gene expression and reduced liver lipids, but also induced peroxisome proliferation in the liver of rats. A similar OFO-induced hepatic peroxisome proliferation has also been observed in Wistar rats fed a $20 \%(\mathrm{w} / \mathrm{w})$ OFO diet, but not a $5 \%$ OFO diet (unpublished data, Chao and Huang). These results indicate that at high intake, OFO used in our studies exhibits typical effects of PPAR $\alpha$ activation in rodents.
The mild peroxisome proliferation response induced by fish oil shown here was comparable to that in previous reports. The ACO activity and mRNA were increased by $1.5-3$ fold in rats fed $15-30 \%(\mathrm{w} / \mathrm{w})$ fish oil-containing diets $(18,29,30)$ and the peroxisome content was increased about 2 fold in rats fed a 30\% fish oil diet for $20 \mathrm{~d}(18)$. In the present study, the upregulation of PPAR $\alpha$ target gene expression and peroxisome proliferation occurred to a higher extent in the OFO-fed rats than in the fish oil-fed rats. In addition, the degree of hepatomegaly was also more severe in the OFO fed rats (1.68 fold that of the HSB control) than in the fish oil-fed rats (1.24 fold that of the HSB control). However, the liver/blood lipid lowering effect displayed by the OFO diet was not superior to the fish oil diet. The reduction level of liver lipids was not different between OFO- and fish oil-fed rats (both showed 60\% reduction in total lipid compared to the HSB control group) and serum cholesterol was not decreased in OFO-fed rats as in fish oil-fed rats (Fig. 4). This result suggested, in addition to PPAR $\alpha$ activation, there are other mechanisms for fish oil to lower liver/blood lipids that might be absent or not efficient in OFO-fed rats.

Fish oil is well known for its hypotriglycemic effect and is considered to be protective against cardiovascular diseases. This favorable effect is mainly from the combined effects of stimulation of fatty acid oxidation and inhibition of lipogenesis in the liver, which are $\operatorname{PPAR} \alpha$-dependent and independent, respectively (31). The n-3 PUFAs, which are abundant in fish oil, increased the transcription of the regulatory enzymes of fatty acid oxidation, such as ACO, CYP450, mediumchain acyl-CoA dehydrogenase (MCAD), acyl-CoA synthetase (ACS), lipoprotein lipase (LPL), and carnitine palmitoyltransferase-I (CPT-I) with activation of PPAR $\alpha$ $(11,31,32)$. On the other hand, they inhibited the transcription of genes coding for lipid synthesis such as fatty acid synthase (FAS), acety-CoA carboxylase (ACC), stearoyl-CoA desaturase (SCD), and S14 through a decrease of nuclear content of sterol regulatory element binding protein-1 (SREBP-1) protein (33-35). Using PPAR $\alpha$-deficient mice, Dallongeville et al. (36) showed that the plasma lipids levels were still decreased by fish oil to a similar extent of wild-type. Thus, they suggested that PPAR $\alpha$ played a minor role in the plasma lipid- and lipoprotein-lowering effect of fish oil (36), a situation different from fibrates (37).

Since the high fresh soybean oil diet did not induce a peroxisome proliferation response, the modified lipid components in the OFO, rather than the 18-C PUFA in the soybean oil, are responsible for the $\operatorname{PPAR} \alpha$-activating effect observed in the OFO-fed rats. The modified components (unidentified fraction as shown in Table 1) accounted for about $5.6 \%$ concentration in the OFO diet. Cyclic fatty acid monomer (CFAM), oxidized fatty acids with oxygenated function, e.g., epoxy, keto, or hydroxy, and even conjugated linoleic acid (CLA) isomers could be PPAR $\alpha$ activators in OFO. CLA activates $\operatorname{PPAR} \alpha$ in transactivation assay, in rat hepatoma cells and in rats $(21,38)$. However, at a level of $1.5 \%(\mathrm{w} / \mathrm{w})$ 
in the diet, CLA did not induce peroxisome proliferation in Sprague-Dawley rats (21). This might be because of the dose. A 5\% OFO diet also up-regulated PPAR $\alpha$ target gene expression (15), but did not induce peroxisome proliferation (Chao and Huang, unpublished data).

This study first observed an increase in peroxisome number in the liver of rats fed a high level of oxidized frying oil. Compared to fish oil, OFO induced a more severe proliferation of peroxisome in the liver, which was paralleled by higher extents of hepatomegaly and increment of two $\operatorname{PPAR} \alpha$ target genes-ACO and CYP4A. As a dietary source, OFO seems to be a more potent peroxisome proliferator than fish oil.

\section{Acknowledgments}

This work was supported by grants NSC91-2320-B039-016 and NSC89-2320-B-002-184 from the National Science Council, Taipei, Taiwan, and CMC91NT-06 from China Medical University, Taichung, Taiwan.

\section{REFERENCES}

1) Nolen GA, Alexander CJ, Artman NR. 1967. Long-term rat feeding study with used frying oil. J Nutr 93: 337348.

2) Poling CE, Eagle E, Rice EE, Durand AMA, Fisher M. 1970. Long-term responses of rats to heat-treated dietary fats: weight gains, food and energy efficiencies, longevity and histopathology. Lipids 5: 128-136.

3) Gonz'alez-Munoz MJ, Bastida S, S'anchez-Muniz FJ. 1998. Short-term in vivo digestibility of triglyceride polymers, dimmers, and monomers of thermoxidized palm olein used in deep-frying. J Agric Food Chem 46: 5188-5193.

4) Marquez-Ruiz G, Guevel G, Dobarganes MC. 1998. Applications of chromatographic techniques to evaluate enzymatic hydrolysis of oxidized and polymeric triglycerides by pancreatic lipase in vitro. J Am Oil Chem Soc 75: 119-126.

5) Huang C, Cheung NS, Lu VR. 1988. Effects of deteriorated frying oil and dietary protein levels on liver microsomal enzymes in rats. J Am Oil Chem Soc 65: 1796-1803.

6) Reddy JK, Lalwai ND. 1983. Carcinogenesis by hepatic peroxisome proliferators: evaluation of the risk of hypolipidemic drugs and industrial plasticizers to humans. Crit Rev Toxicol 12: 1-58.

7) Issemann I, Green S. 1990. Activation of a member of the steroid hormone receptor superfamily by peroxisome proliferators. Nature 347: 645-650.

8) Hashimoto T, Cook WS, Qi C, Yeldandi AV, Reddy JK, Rao MS. 2000. Defect in peroxisome proliferator-activated receptor $\alpha$-inducible fatty acid oxidation determines the severity of hepatic steatosis in response to fasting. J Biol Chem 275: 28918-28928.

9) Kersten S, Seydoux J, Peters JM, Gonzalez FJ, Desvergne B, Wahli W. 1999. Peroxisome proliferator-activated receptor $\alpha$ mediates the adaptive response to fasting. $J$ Clin Invest 103: 1489-1498.

10) Kroetz DL, Yook P, Costet P, Bianchi P, Pineau T. 1998. Peroxisome proliferator-activated receptor $\alpha$ controls the hepatic CYP4A induction adaptive response to starvation and diabetes. J Biol Chem 273: 31581-31589.
11) Schoonjans K, Staels B, Auwerx J. 1996. Role of the peroxisome proliferator-activated receptor (PPAR) in mediating the effects of fibrates and fatty acids on gene expression. J Lipid Res 37: 907-925.

12) Schoonjans K, Staels B, Auwerx J. 1996. The PPARs and their effects on lipid metabolism and adipocyte differentiation. Biochim Biophys Acta 1302: 93-109.

13) Lee SS, Pineau T, Drago J, Lee EJ, Owens JW, Kroetz DL, Fernandez-Salguero PM, Westphal H, Gonzalez FJ. 1995. Targeted disruption of the $\alpha$ isoform of the peroxisome proliferator-activated receptor gene in mice results in abolishment of the pleiotropic effects of peroxisome proliferators. Mol Cell Biol 15: 3012-3022.

14) Dreyer C, Krey G, Keller H, Givel F, Helftenbein G, Wahli W. 1992. Control of the peroxisomal $\beta$-oxidation pathway by a novel family of nuclear hormone receptors. Cell 68: 879-887.

15) Chao PM, Chao CY, Lin FJ, Huang C. 2001. Oxidized frying oil up-regulates hepatic acyl-CoA oxidase and cytochrome P450 4A1 genes in rats and activates PPAR $\alpha$. J Nutr 131: 3166-3174.

16) Chao PM, Hsu SC, Lin FJ, Li YJ, Huang C. 2004. The upregulation of hepatic acyl-CoA oxidase and cytochrome P450 4A1 mRNA expression by dietary oxidized frying oil is comparable between male and female rats. Lipids 39: 233-238.

17) Sulzle A, Hirche F, Eder K. 2004. Thermally oxidized dietary fat up-regulates the expression of target genes of PPAR $\alpha$ in rat liver. J Nutr 134: 1375-1383.

18) Neschen S, Moore I, Regittnig W, Yu CL, Wang Y, Pypaert M, Petersen KF, Shulman GI. 2002. Contrasting effects of fish oil and safflower oil on hepatic peroxisomal and tissue lipid content. Am J Physiol Endocrinol Metab 282: E395-401.

19) Seedorf U, Raabe M, Ellinghaus P, Kannenberg F, Fobker M, Engel T, Denis S, Wouters F, Wirtz KW, Wanders RJ, Maeda N, Assmann G. 1998. Defective peroxisomal catabolism of branched fatty acyl coenzyme A in mice lacking the sterol carrier protein-2/sterol carrier protein-X gene function. Genes Dev 12: 1189-1201.

20) Van den Branden C, Vamecq J, Wybo I, Roels F. 1986. Phytol and peroxisome proliferation. Pediatr Res 20: 411-415.

21) Moya-Camarena SY, Van den Heuvel JP, Belury MA. 1999. Conjugated linoleic acid activates peroxisome proliferator-activated receptor $\alpha$ and $\beta$ subtypes but does not induce hepatic peroxisome proliferation in Sprague-Dawley rats. Biochim Biophys Acta 1436: 331342.

22) Juaneda P, Cordier O, Gregoire S, Sebedio JL. 2001. Conjugated linoleic acid (CLA) isomers in heat-treated vegetable oils. Fondamental 8: 94-97.

23) National Research Council. 1996. Guide for the Care and Use of Laboratory Animals, Publication No. 85-23 (rev.), National Institutes of Health, Bethesda, Maryland.

24) Angermuller S, Fahimi HD. 1981. Selective cytochemical localization of peroxidase, cytochrome oxidase and catalase in rat liver with 3,3'-diaminobenzidine. Histochemistry 71: 33-44.

25) Folch J, Lees M, Sloane Stanley GH. 1957. A simple method for the isolation and purification of total lipids from animal tissues. J Biol Chem 226: 497-509.

26) Small GM, Burdett K, Connock MJ. 1985. A sensitive spectrophotometric assay for peroxisomal acyl-CoA oxi- 
dase. Biochem I 227: 205-210.

27) Singh I. 1997. Biochemistry of peroxisomes in health and disease. Mol Cell Biochem 167: 1-29.

28) Hertz R, Bar-Tana J. 1998. Peroxisome proliferator-activated receptor (PPAR) $\alpha$ activation and its consequences in humans. Toxicol Lett 102-103: 85-90.

29) Baillie RA, Takada R, Nakamura M, Clarke SD. 1999. Coordinate induction of peroxisomal acyl-CoA oxidase and UCP-3 by dietary fish oil: a mechanism for decreased body fat deposition. Prostaglandins Leukot Essent Fatty Acids 60: 351-356.

30) Yamazaki RK, Shen T, Schade GB. 1987. A diet rich in $(n-3)$ fatty acids increases peroxisomal $\beta$-oxidation activity and lowers plasma triacylglycerols without inhibiting glutathione-dependent detoxication activities in the rat liver. Biochim Biophys Acta 920: 62-67.

31) Reddy JK, Mannaerts GP. 1994. Peroxisomal lipid metabolism. Annu Rev Nutr 14: 343-370.

32) Krey G, Braissant O, L'Horset F, Kalkhoven E, Perroud M, Parker MG, Wahli W. 1997. Fatty acids, eicosanoids, and hypolipidemic agents identified as ligands of peroxisome proliferator-activated receptors by coactivatordependent receptor ligand assay. Mol Endocrinol 11: 779-791.

33) Kim HJ, Takahashi M, Ezaki O. 1999. Fish oil feeding decreases mature sterol regulatory element-binding protein 1 (SREBP-1) by down-regulation of SREBP-1c
mRNA in mouse liver. A possible mechanism for downregulation of lipogenic enzyme mRNAs. J Biol Chem 274: 25892-25898.

34) Worgall TS, Sturley SL, Seo T, Osborne TF, Deckelbaum RJ. 1998. Polyunsaturated fatty acids decrease expression of promoters with sterol regulatory elements by decreasing levels of mature sterol regulatory elementbinding protein. J Biol Chem 273: 25537-25540.

35) Xu J, Nakamura MT, Cho HP, Clarke SD. 1999. Sterol regulatory element binding protein-1 expression is suppressed by dietary polyunsaturated fatty acids. A mechanism for the coordinate suppression of lipogenic genes by polyunsaturated fats. J Biol Chem 274: $23577-$ 23583.

36) Dallongeville J, Bauge E, Tailleux A, Peters JM, Gonzalez FJ, Fruchart JC, Staels B. 2001. Peroxisome proliferatoractivated receptor $\alpha$ is not rate-limiting for the lipoprotein-lowering action of fish oil. J Biol Chem 276: 46344639.

37) Peter JM, Hennuyer N, Staels B, Fruchart JC, Fievet C, Gonzalez FJ, Auwerx J. 1997. Alterations in lipoprotein metabolism in peroxisome proliferator-activated receptor $\alpha$-deficient mice. J Biol Chem 272: 27307-27312.

38) Moya-Camarena SY, Vanden Heuvel JP, Blanchard SG, Leesnitzer LA, Belury MA. 1999. Conjugated linoleic acid is a potent naturally occurring ligand and activator of PPAR $\alpha$. J Lipid Res 40: 1426-1433. 